\title{
Féeries
}

Études sur le conte merveilleux, XVII $-\mathrm{XIX}{ }^{\mathrm{e}}$ siècle

\section{The Classic Fairy Tales/The Great Fairy Tale Tradition, from Straparola and Basile to the Brothers Grimm}

Textes rassemblés par Maria Tatar, New York, Norton, 1999, XVIII + 394 p. / textes rassemblés, traduits et édités par Jack Zipes, New York, 2001. XIV $+991 \mathrm{p}$.

Jean Mainil

\section{(2) OpenEdition}

\section{Journals}

Édition électronique

URL : http://journals.openedition.org/feeries/91

DOI : 10.4000/feeries.91

ISSN : 1957-7753

\section{Éditeur}

UGA Éditions/Université Grenoble Alpes

\section{Édition imprimée}

Date de publication : 1 février 2004

Pagination : 209-212

ISSN : 1766-2842

\section{Référence électronique}

Jean Mainil, « The Classic Fairy Tales/The Great Fairy Tale Tradition, from Straparola and Basile to the Brothers Grimm », Féeries [En ligne], 1 | 2004, mis en ligne le 21 février 2007, consulté le 24 septembre 2020. URL : http://journals.openedition.org/feeries/91 ; DOI : https://doi.org/10.4000/feeries.91

Ce document a été généré automatiquement le 24 septembre 2020.

(c) Féeries 


\section{The Classic Fairy Tales/The Great Fairy Tale Tradition, from Straparola and Basile to the Brothers Grimm}

Textes rassemblés par Maria Tatar, New York, Norton, 1999, XVIII + 394 p. / textes rassemblés, traduits et édités par Jack Zipes, New York, 2001. XIV $+991 \mathrm{p}$.

\section{Jean Mainil}

1 Le conte merveilleux en langue française a, de tout temps, eu une grande influence sur le domaine anglo-saxon. Le premier conte de fées littéraire en langue française attesté, un conte encadré dans le roman Histoire d'Hypolite, comte de Duglas de Marie-Catherine d'Aulnoy paru en 1690 sera par exemple traduit dès l'année suivante. Il paraîtra à Londres en 1691 sous le titre de The History of Adolphus, Prince of Russia; and the Princess of Happiness alors que le "conte de fées littéraire " ne constitue pas encore un genre officialisé. Cette influence du domaine français se confirmera à travers tout le dixhuitième siècle avant que des conteurs et des conteuses anglophones ne prennent la relève au XIX siècle, en s'inspirant cependant fort souvent du conte merveilleux en langue française.

D'un point de vue littéraire et culturel, l'influence française sur le conte en langue anglaise est manifeste dans, pour n'en citer qu'une, l'œuvre d'Anne Thackeray, la fille du célèbre romancier qui était lui aussi conteur à ses heures. Signe de la grande influence qu'exerce toujours le conte français sur l'Angleterre de la fin du xix siècle, dans ses Bluebeard's Keys, ou Les Clefs de Barbe Bleue, la conteuse transpose d'une manière originale l'œuvre de Charles Perrault dans une Angleterre victorienne fort éloignée pourtant du faste et des frasques du Versailles contemporain du premier Barbe Bleue. La conteuse anglaise ne se limite pas à l'œuvre du célèbre académicien et reprend aussi, en le mettant à la mode victorienne, un conte de Marie-Catherine d'Aulnoy, Chatte blanche. On pourra relire la Cinderella d'Anne Thackeray (sous son nom de femme mariée Anne 
Isabelle Ritchie) dans une anthologie qui intéressera ceux qui veulent mieux connaître le conte anglais de l'époque victorienne, Victorian Fairy Tales: The Revolt of the Fairies and Elves éditée par Jack Zipes (New York et Londres, Routledge, 1991). Cette "révolte » prend parfois des tournures originales, comme dans ce conte de 1854 que l'on doit à George Cruikshank et qui s'inspire d'un conte de Perrault pour l'intrigue, mais certainement pas pour le détail. Les noces du couple princier servent en effet d'alibi à une discussion sur les effets nocifs des boissons alcoolisées. Le jour des noces, on fait donc un immense brasier où est consumé tout l'alcool du royaume. Tous vécurent de longues années dans le plus grand bonheur et confort, et dans la plus grande sobriété...

3 Au siècle suivant, dans les pays anglo-saxons (comme en France), le conte de fées deviendra plus populaire encore auprès d'un large public sous l'influence des studios Walt Disney. Ici encore l'influence française est très sensible. C'est en effet par le domaine français que Walt Disney commence son œuvre cinématographique avec, en 1922, une production du Chat Botté, Puss in Boots et, la même année, Le Petit Chaperon rouge, Little Red Riding Hood. Avant de se lancer dans une mode "africaniste» ou orientale vaguement (post-)coloniale, les studios produiront encore d'autres blockbusters, des films à succès tels que Cinderella (Cendrillon) en 1950 et Sleeping Beauty, La Belle au Bois dormant neuf ans plus tard.

Dans le domaine académique, le conte en langue française est aussi très présent et on ne compte plus les thèses anglaises et américaines qui lui sont consacrées. Dès le milieu des années 1980, une revue académique, Marvels and Tales se consacrait exclusivement à l'étude du conte de fées, comme l'indique son sous-titre : Journal of Fairy Tale Studies. L'enseignement du conte de fées est rendue possible par les nombreuses traductions de contes merveilleux français et par leur grande disponibilité. Dès 1989, une anthologie rassemblée par Jack Zipes permettait de connaître, en traduction anglaise, le meilleur du conte français. Refondue en 1997 par Signet Classic, Beauty and the Beast and other Classic French Fairy Tales rassemble en plus de quatre cents pages vingt-quatre contes, de Charles Perrault à $\mathrm{M}^{\mathrm{me}}$ Leprince de Beaumont en passant par $\mathrm{M}^{\mathrm{me}}$ de Murat, $\mathrm{M}^{\text {lle }} \mathrm{de}$ Lubert et, bien entendu, $\mathrm{M}^{\mathrm{me}} \mathrm{d}$ 'Aulnoy.

En 1999, la célèbre collection des « Éditions critiques » de la maison d'édition Norton a donné à Maria Tatar la responsabilité d'une anthologie critique consacrée aux Classic Fairy Tales. Spécialiste des frères Grimm et professeur d'allemand à Harvard, Maria Tatar consacrera une bonne partie de son corpus au domaine allemand, incluant des auteurs anglais, russes et italiens, allant de Basile à Margaret Atwood en passant par Oscar Wilde. Le domaine français y est présent, mais il se limite aux deux noms de Perrault et Leprince de Beaumont alors que la Finette Cendron de $\mathrm{M}^{\mathrm{me}} \mathrm{d}$ 'Aulnoy aurait pu trouver sa place dans la catégorie de Cendrillon au même titre que celle de Perrault, sans parler des contes que d'Aulnoy consacre à l'époux monstrueux et qui auraient pu côtoyer le conte de Leprince de Beaumont.

Deux ans plus tard, la même maison d'édition semblait quelque peu vouloir rectifier cette édition en publiant une nouvelle anthologie dont le titre rappelle, en un curieux écho, le titre précédent: The Great Fairy Tale Tradition: from Straparola and Basile to the Brothers Grimm éditée par Jack Zipes. Germaniste et professeur d'allemand à l'université du Minnesota, Jack Zipes est le champion s'il en est du conte français aux États-Unis. Auteur d'anthologies (y compris le volumineux Spells of Enchantment des éditions Penguin en 1991) et d'un grand nombre d'ouvrages consacrés au conte merveilleux, Jack Zipes a traité de sujets aussi variés que « comment briser l'enchantement Disney » 
ou encore "l'inquiétant succès de la littérature pour enfants " où il se penche sur l'inévitable Harry Potter. Dans The Great Fairy Tale Tradition, Jack Zipes a sélectionné, édité et traduit les contes appartenant à la «Grande tradition du conte de fées ». Les catégories selon lesquelles les contes sont répartis assurent à l'anthologie une cohérence thématique et permettent ainsi une perspective comparatiste. Ici, contrairement au premier volume des éditions Norton, le domaine français est très présent et varié. Parmi les 117 contes rassemblés, on n'en compte pas moins de 33 qui proviennent du domaine français. On trouve ainsi, outre Perrault, Marie-Catherine d'Aulnoy, Jean de Mailly, Henriette de Murat, Eustache Le Noble, Marie-Jeanne Lhéritier, Charlotte-Rose Caumont de La Force, Jeanne-Marie Leprince de Beaumont ainsi qu'Antoine Galland.

7 Chaque section est accompagnée d'une introduction qui situe la thématique des contes sélectionnés dans un contexte diachronique, trans-linguistique et trans-national. À la fin $\mathrm{du}$ volume, on trouvera des notes biographiques sur les auteurs, notes assez complètes où se glissent parfois des fautes de dates (on retrouve ainsi d'Aulnoy à la tête d'un complot en 1799, soit près d'un siècle après sa mort en 1705). Puisque le but affiché de l'édition est d'être critique, outre les introductions, notes et notices sur les auteurs, The Great Fairy Tale Tradition inclut également une sélection de sept articles critiques qui reprennent des textes critiques clefs sur le conte de fées. Comme cette sélection remonte jusqu'à la fin du $\mathrm{xIX}^{\mathrm{e}}$ siècle, elle donne une assez bonne idée de l'évolution critique du conte merveilleux. Des voies de recherche sont finalement ouvertes par une bibliographie assez complète à laquelle il faudrait cependant ajouter le travail qu'Anne Defrance a consacré aux contes de $\mathrm{M}^{\mathrm{me}} \mathrm{d}$ 'Aulnoy.

Traduire et éditer une anthologie qui rassemble les « grands » contes de fées à travers les âges, les pays et les langues pour donner un aperçu de la «Grande tradition du conte de fées" en moins de mille pages tenait du pari. Dans The Great Fairy Tale Tradition, Jack Zipes l'a gagné. Bien sûr, il existe tant d'autres contes de fées à traduire et à rassembler. Bien sûr, il existe aussi beaucoup d'autres approches critiques. Contrairement au corpus des contes de fées, la critique reprise ici est essentiellement d'expression anglaise, si ce n'est le dernier article d'abord écrit en langue allemande. Aucun article en langue française n'est ici traduit et inséré. Mais quoi qu'il en soit, on trouvera dans The Great Fairy Tale Tradition un outil de travail, de recherche et d'enseignement indispensable pour qui s'intéresse au conte de fées considéré dans une perspective comparatiste, sans pour autant négliger l'immense contribution du domaine français au conte merveilleux. 